\title{
A!
}

This is an electronic reprint of the original article.

This reprint may differ from the original in pagination and typographic detail.

Brillson, L.J.; Dong, Yufeng; Tuomisto, F.; Svensson, B.G.; Kuznetsov, A.Yu.; Doutt, D.; Mosbacker, H.L.; Cantwell, G.; Zhang, Jizhi; Song, J.J.; Fang, Z.-Q.; Look, D.C.

Interplay of native point defects with ZnO Schottky barriers and doping

Published in:

Journal of Vacuum Science and Technology. Part B.

DOI:

$10.1116 / 1.4732531$

Published: 01/01/2012

Document Version

Publisher's PDF, also known as Version of record

Please cite the original version:

Brillson, L. J., Dong, Y., Tuomisto, F., Svensson, B. G., Kuznetsov, A. Y., Doutt, D., Mosbacker, H. L., Cantwell, G., Zhang, J., Song, J. J., Fang, Z-Q., \& Look, D. C. (2012). Interplay of native point defects with ZnO Schottky barriers and doping. Journal of Vacuum Science and Technology. Part B., 30(5), 1-11. [050801].

https://doi.org/10.1116/1.4732531

This material is protected by copyright and other intellectual property rights, and duplication or sale of all or part of any of the repository collections is not permitted, except that material may be duplicated by you for your research use or educational purposes in electronic or print form. You must obtain permission for any other use. Electronic or print copies may not be offered, whether for sale or otherwise to anyone who is not an authorised user. 


\section{Interplay of native point defects with ZnO Schottky barriers and doping}

Leonard J. BrillsonYufeng DongFilip TuomistoBengt G. Svensson and Andrei Yu. KuznetsovDaniel Doutt and $\mathrm{H}$. Lee MosbackerGene Cantwell, Jizhi Zhang, and Jin Joo SongZ.-Q. FangDavid C. Look

Citation: Journal of Vacuum Science \& Technology B, Nanotechnology and Microelectronics: Materials, Processing, Measurement, and Phenomena 30, 050801 (2012); doi: 10.1116/1.4732531

View online: http://dx.doi.org/10.1116/1.4732531

View Table of Contents: http://avs.scitation.org/toc/jvb/30/5

Published by the American Vacuum Society

\section{Articles you may be interested in}

ZnO Schottky barriers and Ohmic contacts

Journal of Applied Physics 109, 121301 (2011); 10.1063/1.3581173

\section{Instruments for Advanced Science}

Contact Hiden Analytical for further details: W www.HidenAnalytical.com E info@hiden.co.uk CLICK TO VIEW our product catalogue

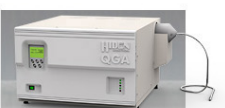

Gas Analysis dynamic measurement of reaction gas streams ' cataysis and thermal analysis - molecuar beam studes dissolved species probes fermentation, envirormental and ecological stud

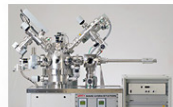

Surface Science UHVTPD , end point detection in in beam etch , elemental imaging-sufface mapping

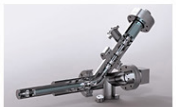

Plasma Diagnostics , plasma source characterization etch and deposition process reaction kinetic studies

analysis of neutral and radical species

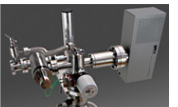

Vacuum Analysis partial pressure measurement and control of process gases reactive sputter process control vacuum diagnostic 


\title{
Interplay of native point defects with ZnO Schottky barriers and doping
}

\author{
Leonard J. Brillson a) \\ Department of Electrical and Computer Engineering and Department of Physics, The Ohio State University, \\ Columbus, Ohio 43210 \\ Yufeng Dong \\ Department of Electrical and Computer Engineering, The Ohio State University, Columbus, Ohio 43210
}

Filip Tuomisto

Department of Applied Physics, Aalto University, P.O. Box 11100, FI-00076 Aalto, Finland

Bengt G. Svensson and Andrei Yu. Kuznetsov

Department of Physics, University of Oslo, P.O. Box 1048, Blindern, 0316 Oslo, Norway

Daniel Doutt and H. Lee Mosbacker

Department of Physics, The Ohio State University, Columbus, Ohio 43210

Gene Cantwell, Jizhi Zhang, and Jin Joo Song

ZN Technology, Inc., 910 Columbia St., Brea, California 92821

\section{Z.-Q. Fang}

Semiconductor Research Center, Wright State University, Dayton, Ohio 45433

David C. Look

Semiconductor Research Center, Wright State University, Dayton, Ohio 45433 and Materials and Manufacturing Directorate, Air Force Research Laboratory, Wright-Patterson AFB, Ohio 45433

(Received 15 February 2012; accepted 15 June 2012; published 29 June 2012)

\begin{abstract}
A combination of depth-resolved electronic and structural techniques reveals that native point defects can play a major role in $\mathrm{ZnO}$ Schottky barrier formation and charged carrier doping. Previous work ignored these lattice defects at metal- $\mathrm{ZnO}$ interfaces due to relatively low point defect densities in the bulk. At higher densities, however, they may account for the wide range of Schottky barrier results in the literature. Similarly, efforts to control doping type and density usually treat native defects as passive, compensating donors or acceptors. Recent advances provide a deeper understanding of the interplay between native point defects and electronic properties at $\mathrm{ZnO}$ surfaces, interfaces, and epitaxial films. Key to $\mathrm{ZnO}$ Schottky barrier formation is a massive redistribution of native point defects near its surfaces and interfaces. It is now possible to measure the energies, densities, and in many cases the type of point defects below the semiconductor-free surface and its metal interface with nanoscale precision. Depth-resolved cathodoluminescence spectroscopy of deep level emissions calibrated with electrical techniques show that native point defects can (1) increase by orders of magnitude in densities within tens of nanometers of the semiconductor surface, (2) alter free carrier concentrations and band profiles within the surface space charge region, (3) dominate Schottky barrier formation for metal contacts to $\mathrm{ZnO}$, and (4) play an active role in semiconductor doping. The authors address these issues by clearly identifying transition energies of leading native point defects and defect complexes in $\mathrm{ZnO}$ and the effects of different annealing methods on their spatial distributions on a nanoscale. These results reveal the interplay between $\mathrm{ZnO}$ electronic defects, dopants, polarity, and surface nanostructure, highlighting new ways to control ZnO Schottky barriers and doping. (C) 2012 American Vacuum Society. [http://dx.doi.org/10.1116/1.4732531]
\end{abstract}

\section{INTRODUCTION}

The semiconductor $\mathrm{ZnO}$ is a prime candidate for next generation opto- and microelectronics. Applications include blue/UV light emitting diodes, lasers, transparent conducting

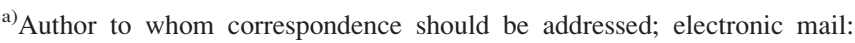
brillson.1@osu.edu
}

oxides, field effect transistors, biosensors, spintronics, and other nanoscale devices. Furthermore, $\mathrm{ZnO}$ possesses advantages over other semiconductors in terms of low cost, ease of growth, and wet chemical processing, as well as biocompatibility. The rapid development of $\mathrm{ZnO}$ electronic device applications ${ }^{1-3}$ has increased the need to understand and control its contact and doping properties. Here we review key challenges to $\mathrm{ZnO}$ Schottky barrier formation and 
doping, and we present results that highlight the interplay of native point defects with these electronic properties. $\mathrm{ZnO}$ provides an excellent test bed for such studies since one can obtain a wide range of Schottky barriers, carrier densities, and defect concentrations to distinguish between physical mechanisms. Several review articles on the nature of $\mathrm{ZnO}$ physical properties, ${ }^{4}$ native point defects, ${ }^{5}$ impurities and excitons, ${ }^{6}$ Schottky barrier formation and Ohmic contacts, ${ }^{7}$ and the relation of its interface properties to those of other compound semiconductors ${ }^{8,9}$ are now available. Key to evaluating the impact of various mechanisms is the ability to probe defect densities and carrier concentrations on a nanometer scale. We have used depth-resolved cathodoluminescence spectroscopy (DRCLS) on this scale combined with electrical, electronic, and chemical techniques to measure the impact of native point defects on contact rectification and doping. In terms of Schottky barriers, DRCLS reveals defect formation at metal- $\mathrm{ZnO}$ interfaces and corresponding changes in carrier densities that depend on the detailed interface chemical bonding on a microscopic scale. In terms of doping, DRCLS enables the identification of characteristic $\mathrm{ZnO}$ native point defects that are directly involved in degenerate donor doping, acceptor doping, as well as the sensitive dependence of free carrier density on specific annealing methods. Beyond the examples included in this review, we discuss new directions for controlling $\mathrm{ZnO}$ Schottky barriers and doping.

\section{SCHOTTKY BARRIER INFLUENCE OF SURFACES AND INTERFACES}

The study of $\mathrm{ZnO}$ Schottky barriers extends back to the 1960s with often conflicting results extending over a wide range of values. ${ }^{7,9,10}$ For semiconductors in general, the classical Schottky barrier height $\Phi_{\mathrm{SB}}$ at a metal-semiconductor junction given by $\Phi_{\mathrm{SB}}=\Phi_{M}-\chi_{\mathrm{SC}}$, where $\Phi_{M}$ is the metal work function and $\chi_{\mathrm{SC}}$ is the semiconductor electron affinity, is modified by an interface dipole $\Delta \chi$ due to a variety of extrinsic effects ${ }^{9}$. such that $\Phi_{\mathrm{SB}}=\Phi_{M}-\chi_{\mathrm{SC}}-\Delta \chi$. Such extrinsic effects are reflected in contacts to $\mathrm{ZnO}$, where recent studies display major differences in $\Phi_{\mathrm{SB}}$ even for the same metal on the same $\mathrm{ZnO}$ surface. For example, Fig. 1 illustrates the highest reported current-voltage $(I-V)$ barrier heights $\Phi_{\mathrm{SB}}^{I-V}$ for different metals on different oriented surfaces of single crystal $\mathrm{ZnO} .{ }^{11}$ Even for the same metal on the same orientation, $\Phi_{S B}^{I-V}$ can vary by several tenths of an eV. Thus Fig. 1 shows $\Phi_{\mathrm{SB}}^{I-V}$ for Pt varying from 0.97 to $0.7 \mathrm{eV}$. Furthermore, there is a considerable variation in ideality factor $n$ due to image force lowering, thermionic field emission, and/or lateral contact inhomogeneity such that $\Phi_{\mathrm{SB}}^{I-V}$ decreases with increasing $n$. Ideality factor variations between 1 and 2 are commonly attributed to recombination via gap states. ${ }^{12}$ Higher $n$ values can also be attributed to defect state recombination, ${ }^{13}$ as well as trap-assisted tunneling, ${ }^{14,15}$ nonlinear shunts, or edge currents. ${ }^{16}$ Defects that increase the net carrier density can also enhance tunneling by decreasing the width of the semiconductor's depletion region. Assuming uniform semiconductor composition, variations in image force lowering,

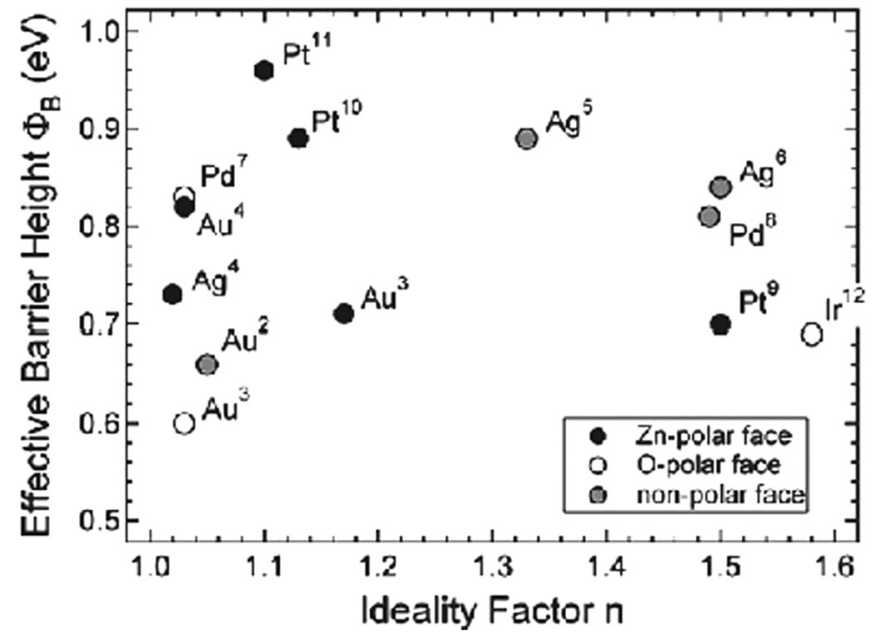

FIG. 1. Maximum values of $\Phi_{\mathrm{SB}}^{n}$ and $n$ obtained from $I-V$ measurements for various metals on $\mathrm{ZnO}$ showing the wide range of values for the same metal. Reprinted with permission from M. W. Allen, S. M. Durbin, and J. B. Metson, Appl. Phys. Lett., 91, 053512, 2007. Copyright 2007, American Institute of Physics.

semiconductor work function, and band bending can be attributed to surface dipole changes due to local electronic states near the semiconductor surface or induced at the surface by adsorbates. In each case, localized electronic states are involved. These states can alter the potential difference and hence the barrier between metal and semiconductor, or they can decrease the effective barrier by variety of trap-assisted tunneling processes. In the case of $\mathrm{Ag}$, higher $\Phi_{\mathrm{SB}}^{I-V}$ may also be due to formation of $\mathrm{Ag}$ oxide interlayers ${ }^{17}$ or an increase in effective work function. ${ }^{18}$

The same metal on the same $\mathrm{ZnO}$ surface can also exhibit significant $\Phi_{\mathrm{SB}}^{I-V}$ and capacitance-voltage-measured $\Phi_{\mathrm{SB}}^{C-V}$ variations. Figure 2 illustrates the difference between $\Phi_{\mathrm{SB}}^{I-V}$ and $\Phi_{\mathrm{SB}}^{C-V}$ for Pd diodes on $\mathrm{ZnO} .{ }^{19}$ The lower $\Phi_{\mathrm{SB}}^{I-V}$ are due to inhomogeneities within a single diode area that weight conduction preferentially through lower barrier patches. The fluctuations in $\Phi_{\mathrm{SB}}$ can be modeled by a Gaussian distribution of barrier heights with a standard deviation around a mean value and a temperature-dependent effective barrier height $\Phi_{\mathrm{SB}, \text { eff }}(T)$. The inset shows the difference between $\Phi_{\mathrm{SB}, \text { eff }}(T)$ and $\Phi_{\mathrm{SB}}^{C-V}$ versus temperature such that extrapolation to the origin yields a standard deviation of barrier height and thereby a method to quantify barrier height inhomogeneity.

$\mathrm{ZnO}$ surface orientation also has a strong influence on $\Phi_{\mathrm{SB}}^{I-V}$. Figure 3 illustrates the variation of $\Phi_{\mathrm{SB}}^{I-V}$ for $\mathrm{Ag}$ (oxide) on $\mathrm{Zn}$ - vs O-polar $\mathrm{ZnO}$, showing a $0.2 \mathrm{eV}$ higher $\mathrm{Zn}$ polar barrier for all diodes, regardless of $n .{ }^{11}$ The decrease in $\Phi_{\mathrm{SB}}^{I-V}$ with increasing $n$ again indicates extrinsic states near the interface reducing the effective $\Phi_{\mathrm{SB}}$.

Early measurements of $\mathrm{ZnO} \Phi_{\mathrm{SB}}^{I-V}$ and $\Phi_{\mathrm{SB}}^{C-V}$ for different metals without air exposure display a wide range of values that are in contrast to the much smaller range found for the same metals on more covalent semiconductors such as GaAs. ${ }^{20}$ A characteristic transition from low to high $\Phi_{\mathrm{SB}}$ common to $\mathrm{ZnO}$ and other compound semiconductors was found with an interface heat of reaction $\Delta H_{R} \cdot{ }^{21,22}$ In turn, 


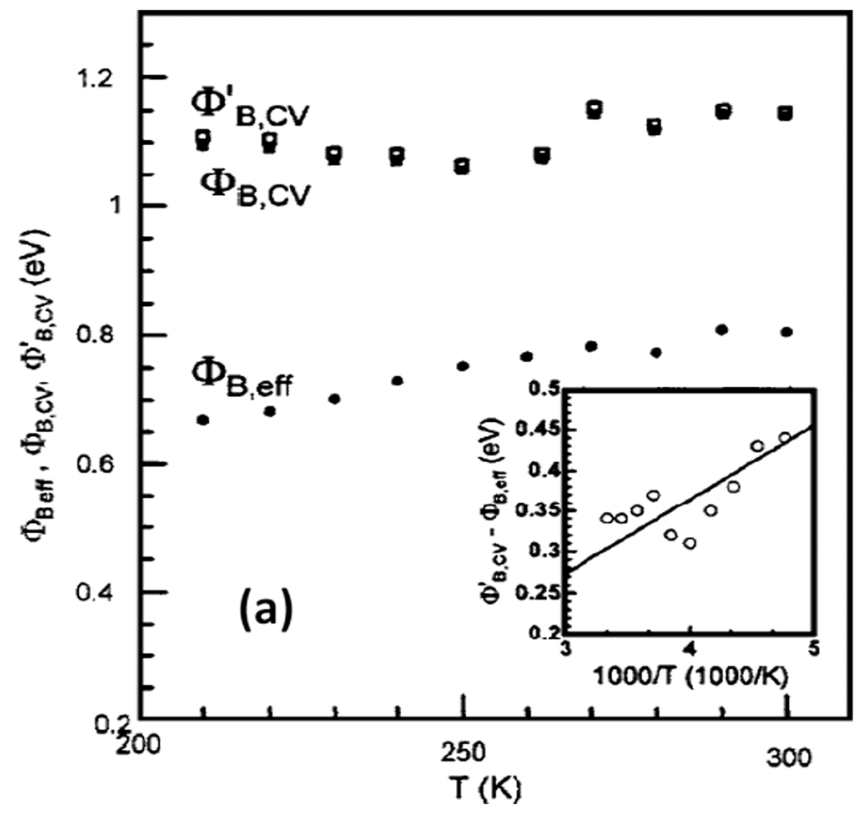

FIG. 2. Effective $\Phi_{\mathrm{SB}, \text { eff }}, \Phi_{\mathrm{SB}, C-V}$, and $\Phi_{\mathrm{SB}, C-V}^{\prime}$ vs temperature for $\mathrm{Pd} / \mathrm{ZnO}(0001)$. The inset plots the difference between $\Phi_{\mathrm{SB}, \text { eff }}$ and $\Phi_{\mathrm{SB}, C-V}^{\prime}$ such that a line through the origin yields a standard deviation of barrier height. Reprinted with permission from H. von Wenckstern, G. Biehne, R. A. Rahman, H. Hochmth, M. Lorenz, and M. Grundmann, Appl. Phys. Lett., 88, 092102, 2006. Copyright 2006, American Institute of Physics.

this thermodynamic relation suggests that chemical interactions at the metal-ZnO interface can play a role in barrier formation. Similarly, the barriers for metals on chemically treated $\mathrm{ZnO}$ do not seem to follow the difference in work functions. ${ }^{23}$ They attributed the much larger ideality factors for these diodes either to tunneling, interface states, and/or the presence of deep recombination centers.

In general, these variations in $\Phi_{\mathrm{SB}}$ for $\mathrm{ZnO}$ (and other semiconductors) can be understood in terms of multiple transport mechanisms at the metal interface. Figure 4 illustrates schematically the major pathways for transport across the metal-semiconductor interface. Charge can transfer from the metal into the semiconductor either over the barrier (thermionic emission), through the barrier by tunneling (field

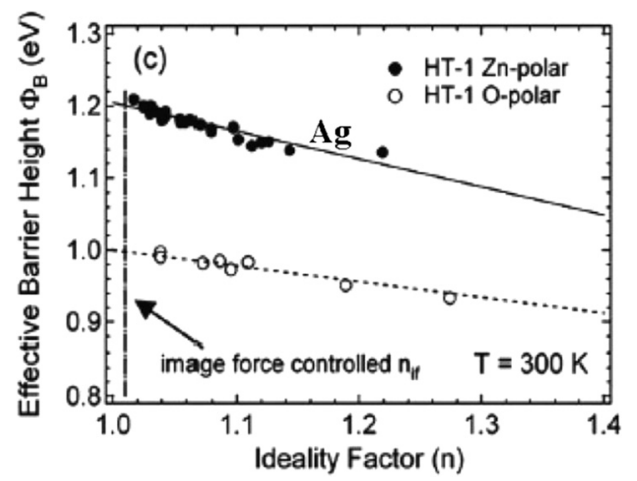

FIG. 3. Effective $\mathrm{Ag}-\mathrm{ZnO} \Phi_{\mathrm{SB}}^{n}$ for hydrothermal $\mathrm{ZnO}$ for opposite polar orientations showing consistently higher $\mathrm{Zn}$ - vs O-polar $\Phi_{\mathrm{SB}}^{n}$, both increasing with decreasing $n$. Reprinted with permission from M. W. Allen, S. M. Durbin, and J. B. Metson, Appl. Phys. Lett., 91, 053512, 2007. Copyright 2007, American Institute of Physics.

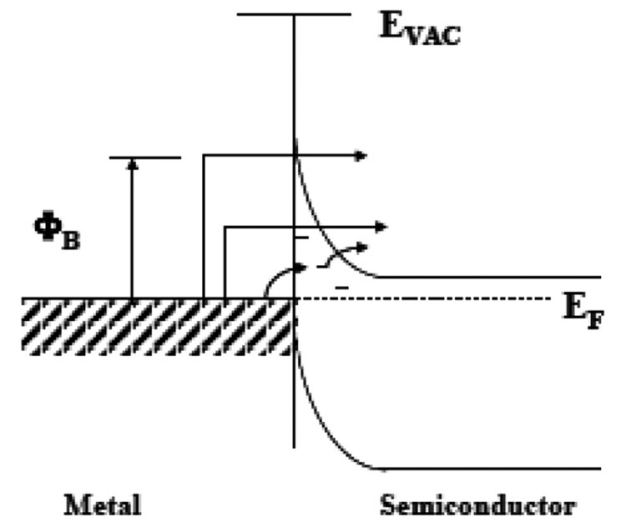

FIG. 4. Complementary charge transport mechanisms in $\mathrm{ZnO}$ including thermionic emission, tunneling, and hopping transport through defect levels in the bandgap. Reprinted with permission from L. J. Brillson and Y. Lu, J. Appl. Phys., 109, 121301, 2011. Copyright 2011, American Institute of Physics.

emission), a combination of the two (thermionic field emission), and through the barrier by hopping through gap states within the semiconductor space charge region, termed trapassisted tunneling. The metal-semiconductor interface without applied voltage, i.e., with Fermi levels aligned, and only for charge transport from the metal to the semiconductor is commonly used to illustrate the internal photoemission spectroscopy method for measuring Schottky barrier heights. ${ }^{24}$ Analogous illustrations of thermionic and thermionic field emission under forward or reverse bias are commonly shown in textbooks, ${ }^{25}$ albeit without trap-assisted tunneling. ${ }^{14,15}$ Increased doping in the surface space charge region decreases the depletion width, thereby increasing thermionic field, field emission, and trap-assisted or hopping transport through the barrier. The results presented in the sections to follow provide evidence that electrically active native point defects near the intimate metal-semiconductor interface can form that (1) alter the carrier concentration and change the surface space charge region to influence tunneling and (2) introduce new gap states within the bandgap that can promote hopping transport. Likewise, following sections provide evidence that the presence of native point defects either at a growing $\mathrm{ZnO}$ surface or within the bulk can enable $\mathrm{ZnO}$ doping by providing lattice vacancy sites for dopant atoms to fill.

\section{EXPERIMENTAL METHODS}

In order to probe defects and doping near surfaces, interfaces, and within thin films on a nanometer scale, we used a combination of techniques centered on DRCLS with single crystal $\mathrm{ZnO}$ provided by numerous vendors. The DRCLS technique typically employs a relatively low energy electron beam to excite electronic transitions at depths below a free surface that are controllable on a nanometer scale. ${ }^{26-28}$ Briefly, an incident electron beam introduces a cascade of secondary electrons that produce electron-hole pairs that recombine and produce optical luminescence at characteristic depths. Figure 5 illustrates a Monte Carlo simulation that includes backscattering of the rate of energy loss due to the electron-hole pair creation. ${ }^{29}$ With increasing incident beam 


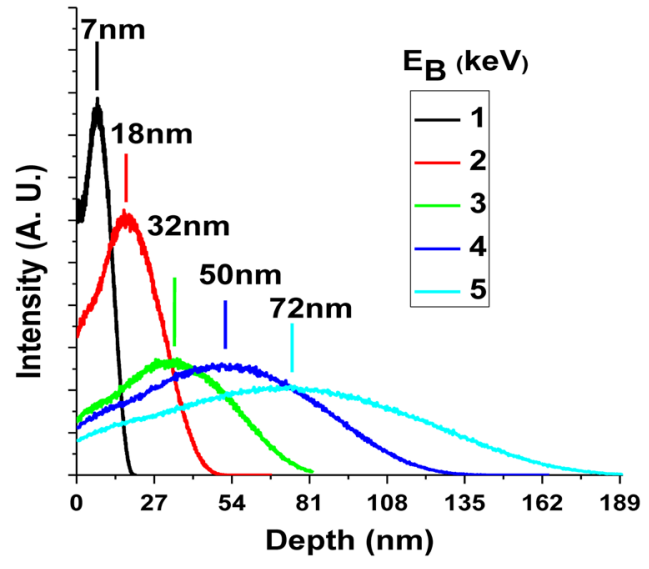

FIG. 5. (Color online) Monte Carlo simulations for rate of energy loss due to electron-hole pair creation in $\mathrm{ZnO}$ for $E_{B}=1-5 \mathrm{keV}$.

energy $E_{B}$, excitation can occur at a surface, an interface below the surface, or deep within the bulk semiconductor. The resultant emission energies are characteristic of band-toband, band-to-defect, as well as interface-specific transitions. At $E_{B}$ of a few kilovolts or less, excitation depths can be controlled on a scale of tens of nanometers or less. This control permits investigation of both ultrathin layers as well as micrometer-thick materials. Evidence from both depth ranges contribute to the results presented here. The electron beam creates a cascade of secondary electrons in three dimensions, "blooming" laterally with increasing depth. To compensate for such volume changes, all defect spectra are normalized with respect to near-band edge (NBE) peak intensities. As Fig. 5 shows, the depth range of excitation also becomes wider with increasing $E_{B}$. For $E_{B}>5 \mathrm{keV}$, DRCLS depth resolution is improved with a relatively simple differential method: renormalizing spectra from shallower layers for subtraction from deeper layer spectra, resulting in depth resolution comparable to other depth-resolved techniques. ${ }^{30}$ Measurements of depthresolved cathodoluminescence (DRCL) spectra versus metal thickness show no distortion of spectra features through the metal diodes due to attenuation or internal reflection.

Several other experimental techniques complement DRCLS to describe how native point defects impact ZnO's electronic properties. Positron annihilation spectroscopy (PAS) provides densities of $\mathrm{Zn}$ vacancies and vacancy clusters as a function of depth. ${ }^{31,32}$ Hall measurements coupled with modeling provide detailed values of donors and acceptors for our $\mathrm{ZnO}$ samples as a function of growth and processing conditions. ${ }^{33,34} I-V$ (Refs. 35 and 36) provides a $\Phi_{\mathrm{SB}}^{I-V}$, while $C-V$ (Refs. $37-40$ ) provides both $\Phi_{\mathrm{SB}}^{C-V}$ as well as net carrier densities as a function of depth. Deep level optical spectroscopy (DLOS) ${ }^{41}$ and surface photovoltage spectroscopy (SPS $)^{42,43}$ provide information on energy levels within the $\mathrm{ZnO}$ bandgap that correspond with the optical emission energies detected by DRCLS, often within $100 \mathrm{meV}$, notwithstanding possible Franck-Condon shifts.

Schottky barrier studies employed $\mathrm{ZnO}$ single crystal wafers grown by vapor phase transport from ZN Technology, Inc. These exhibit typical defect density luminescence intensities several orders of magnitude below those of the NBE emission. Degenerate $n$-type doping studies employed films grown by pulsed laser deposition (PLD) under argon or forming gas ambients. Li-doped studies employed both Li-doped melt-grown- (MG) and hydrothermal (HT)-ZnO with different temperature anneals and cooling rates, as described in Sec. VI.

\section{SUBSURFACE AND INTERFACE DEFECTS}

DRCLS studies of $\mathrm{ZnO}$ single crystals from numerous sources reveal defect emission intensities that can vary by orders of magnitude relative to NBE emissions within the bulk and that lie deep within the energy bandgap. ${ }^{27}$ Calculations of formation energy for the most common native point defects in $\mathrm{ZnO}$ indicate that zinc vacancies $\left(V_{\mathrm{Zn}}\right)$ and oxygen vacancies $\left(V_{\mathrm{O}}\right)$ are energetically the most favorable under O-rich or Zn-rich conditions, respectively, under $n$-type conditions. ${ }^{44,45}$ Indeed, both have relatively low formation energies under both conditions. Hybrid Hartree-Fock density function first-principles theory positions the energy levels of these defects above midgap for the $2^{+} / 0 V_{\mathrm{O}}$ transition energy and below midgap for $0 /-V_{\mathrm{Zn}}$ transition energy. ${ }^{44}$

There is considerable electronic evidence that carrier densities can increase by orders of magnitude near metal- $\mathrm{ZnO}$ interfaces. For example, a $1 / C^{2}-V$ plot of net carrier density at $\mathrm{Ir}-\mathrm{ZnO}(000 \overline{1})$ contacts reveals a threefold increase in electron density from a depth of 200 to $90 \mathrm{~nm}$, reaching $10^{17} \mathrm{~cm}^{-3}$ at $90 \mathrm{~nm}$ with an increasing slope that suggests at least an order of magnitude higher density at the metal interface. Even at $10^{17} \mathrm{~cm}^{-3}$, such carrier densities are comparable or larger than bulk doping densities. Forward current leakage prevents measurements at even shallower depths. DRCLS excitation at depths of 200 to $\sim 50 \mathrm{~nm}$ reveals threefold midgap defect increases that correspond to the $1 / C^{2}-V$ data. DLOS and deep level transient spectroscopy (DLTS) measurements exhibit energy level transitions that correspond to the DRCLS features under bias conditions that probe comparable depths. $^{46}$

At $\mathrm{Pd}-\mathrm{ZnO}(0001)$ contacts with relatively low native point defect emissions, DRCL spectra exhibit a midgap defect emission at $2.45 \mathrm{eV}$ that grows more than twofold with decreasing excitation depth in the $<20-100 \mathrm{~nm}$ range. $1 / C^{2}-V$ net carrier concentrations exhibit a corresponding increase by $>2-5 \times$ from the bulk to $\sim 70-80 \mathrm{~nm}$. Similarly, an $E_{C}-E_{S}=0.5 \mathrm{eV}$ trap measured by DLTS at this junction appears and grows by $>2 \times$ from 150 to $60-90 \mathrm{~nm}^{38}$ Taken together, these results show that near-surface defects can introduce new donors. Thus nanoscale DRCLS reveals subsurface native point defects whose densities can vary by orders of magnitude as seen from (1) deep level optical emission, (2) carrier densities, and (3) trap densities. These subsurface and interface defect densities are large enough to impact Schottky barriers.

Although $1 / C^{2}-V$ measurements often reveal increased defect densities within tens of nanometers of surfaces and interface, such variations can depend on surface polarity, interface preparation, subsequent process, and the variations 
in defect densities versus depth within the initial $\mathrm{ZnO}$ crystal. ${ }^{7}$ Thus, for example, Pd diodes on hydrothermally grown $\mathrm{ZnO}$ can exhibit decreased near-junction carrier densities, ${ }^{47}$ and Ag oxide contacts to hydrothermally grown, highly compensated as well as melt-grown $\mathrm{ZnO}$ showed little change within $\sim 50 \mathrm{~nm}$ of the surface. ${ }^{17}$ Likewise, remote oxygen plasma treatments that increase compensating defects can decrease net carrier density as described in the following. ${ }^{38}$

\section{METAL-INDUCED DEFECTS AND SCHOTTKY BARRIERS}

The densities of native point defects at the nanoscale metal- $\mathrm{ZnO}$ interface can be directly related to the corresponding Schottky barrier heights measured macroscopically. To illustrate the correlation of defects with $\Phi_{\mathrm{SB}}^{I-V}$, consider atomically clean $\mathrm{ZnO}$ contacts with the common metals $\mathrm{Al}$ and $\mathrm{Au}$, which produce Ohmic versus rectifying behavior, respectively, when deposited on the same $\mathrm{ZnO}$ surface. Figure 6(a) shows a comparison of DRCL spectra for an $\mathrm{Al}-\mathrm{ZnO}$ diode interface versus the bare $\mathrm{ZnO}$ surface within a few nanometers of the diode. ${ }^{36}$. This diode exhibits Ohmic behavior with nearly equal forward and reverse current characteristics. At room temperature, the bare surface exhibits an NBE transition at $3.36 \mathrm{eV}$ and phonon replicas extending to lower energies plus midgap emission at $\sim 2.5 \mathrm{eV}$ that is more than 3 orders of magnitude lower than the NBE intensity. Under the Al diode, this midgap emission intensity increases by an order of magnitude. In contrast, an $\mathrm{Au}$ diode on the same surface has a rectifying $\Phi_{\mathrm{SB}}=0.48 \mathrm{eV}$ and negligible change in this $\sim 2.5 \mathrm{eV}$ emission under the $\mathrm{Au}$ diode at room temperature even though peak excitation for $E_{B}=5 \mathrm{keV}$ through $\mathrm{Au}$ is tens of nanometers closer to the interface. Since DRCLS showed uniformly low defects from the surface extending hundreds of nanometers into the $\mathrm{ZnO}$, the dramatically higher defect densities induced by $\mathrm{Al}$ compared to the relatively unchanged defect emission for Au can only be attributed to the creation of new defects by Al. Furthermore, as depth-dependent carrier density measurements will show, these metal-induced changes can extend tens of nanometers away from the interface due to atom and/or defect segregation, the nature of which is currently under investigation.

After annealing at higher temperature, however, the $\mathrm{Au}$ diode characteristic changes dramatically. ${ }^{36}$ The room temperature $I-V$ characteristic remains rectifying until temperatures above $550{ }^{\circ} \mathrm{C}$, where the reverse current increases by more than 2 orders of magnitude. Figure 6(b) shows that a new defect feature appears at $\sim 1.9 \mathrm{eV}$ at $T=650^{\circ} \mathrm{C}$, exceeding by 2 orders of magnitude the background emission at that energy for the unannealed junction. We attribute this $\sim 1.9 \mathrm{eV}$ emission to $V_{\mathrm{Zn}}$-related defects since the $\mathrm{Au}-\mathrm{Zn}$ phase diagram includes an eutectic at $642{ }^{\circ} \mathrm{C} .{ }^{48}$ Formation of this eutectic must involve $\mathrm{Zn}$ atoms from the $\mathrm{ZnO}$ adjacent to the Au diode. Diffusion of $\mathrm{Zn}$ out of the $\mathrm{ZnO}$ into the $\mathrm{Au}$ layer then would leave behind $V_{\mathrm{Zn}}$ sites and account for the appearance of new gap state emission. These defects reside within a few nanometers of the $\mathrm{Au}-\mathrm{ZnO}$ junction and are
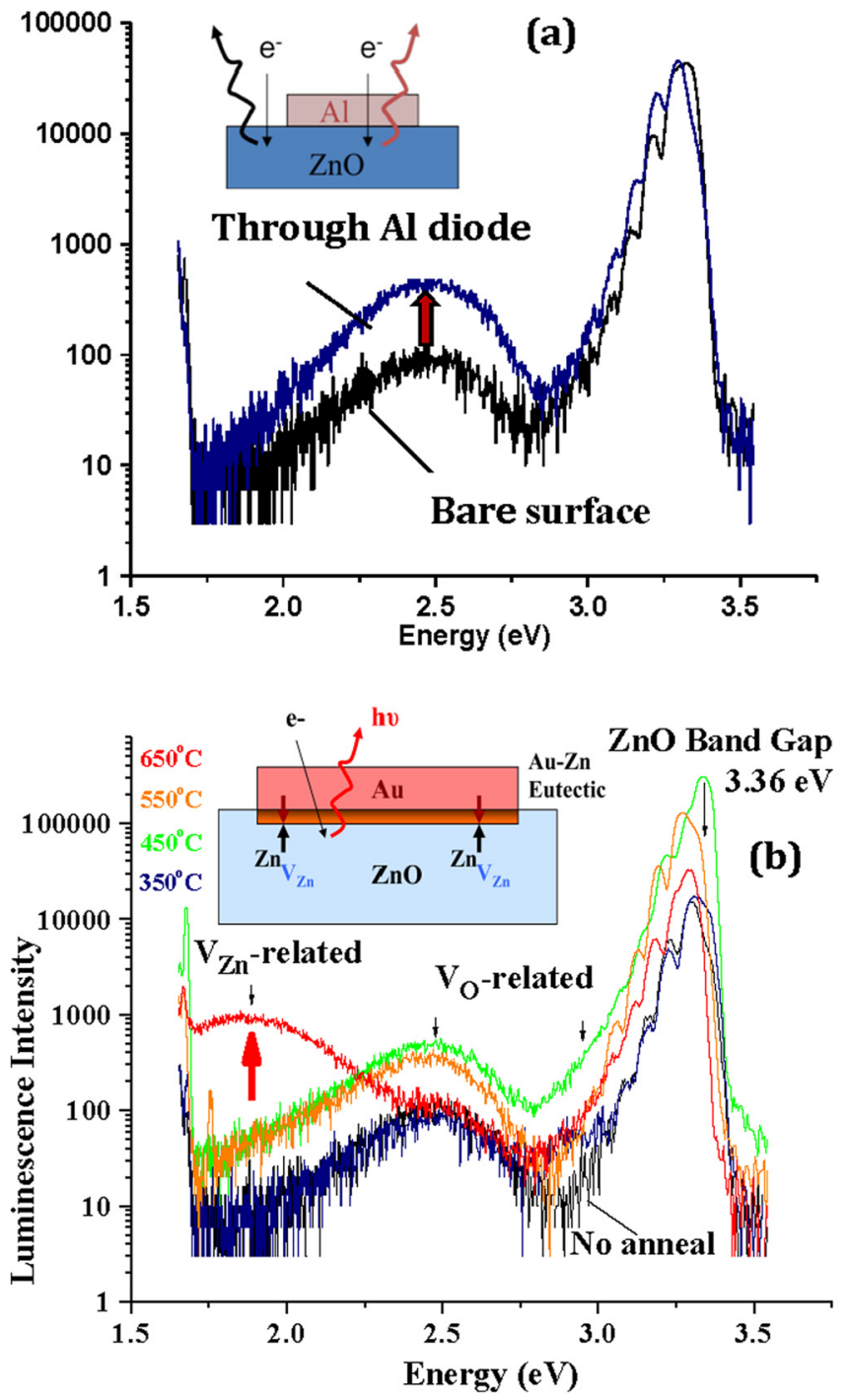

FIG. 6. (Color online) (a) Micro-cathodoluminescence (CL) spectra of bare $\mathrm{ZnO}(000 \overline{1})$ through vs at the periphery of an $\mathrm{Al}$ diode showing the increase of defect emission at the $\mathrm{Al} / \mathrm{ZnO}$ interface. (b) Micro-CL spectra of bare $\mathrm{ZnO}(000 \overline{1})$ through vs at the periphery of an Au diode showing the increase of defect emission at the $\mathrm{Au} / \mathrm{ZnO}$ interface above the threshold for $\mathrm{Au}-\mathrm{Zn}$ eutectic formation. Reprinted with permission from H. L. Mosbacker, S. El Hage, M. Gonzalez, S. A. Ringel, M. Hetzer, D. C. Look, G. Cantwell, J. Zhang, J. J. Song, and L. J. Brillson, J. Vac. Sci. Technol. B, 24, 1405, 2007. Copyright 2007, American Institute of Physics.

detectable because DRCLS can probe the first few nanometers of $\mathrm{ZnO}$ below the $\mathrm{Au}-\mathrm{ZnO}$ interface selectively.

Native point defects can also account for the significant differences in $\Phi_{\mathrm{SB}}$ between $\mathrm{Zn}$ and $\mathrm{O}$ surface polarities. Figure 7 illustrates $1 / C^{2}-V$ determination of $\Phi_{\mathrm{SB}}$ from extrapolated intercepts to the baseline for $\mathrm{Pd}$ and $\mathrm{Au}$ on $\mathrm{Zn}$ - and O-polar $\mathrm{ZnO}$ surfaces of the same crystal. ${ }^{37} \mathrm{C}-\mathrm{V}$-measured barriers have fewer artifacts than $I-V$ measurements since barrier inhomogeneities and current leakage through low barrier regions are avoided. For the Pd diode, the $\mathrm{Zn}$-polar face exhibits a $0.05 \mathrm{eV}$ higher $\Phi_{\mathrm{SB}}$ than the O-polar face. For the Au diode, $\mathrm{Zn}$-polar face has a $0.13 \mathrm{eV}$ higher $\Phi_{\mathrm{SB}}$. The net carrier densities in the $\mathrm{ZnO}$ near the metal diodes can account for these differences in $\Phi_{\mathrm{SB}}$. Figure 7 (inset) shows net carrier densities obtained from $1 / C^{2}-V$ measurements that exhibit a clear 


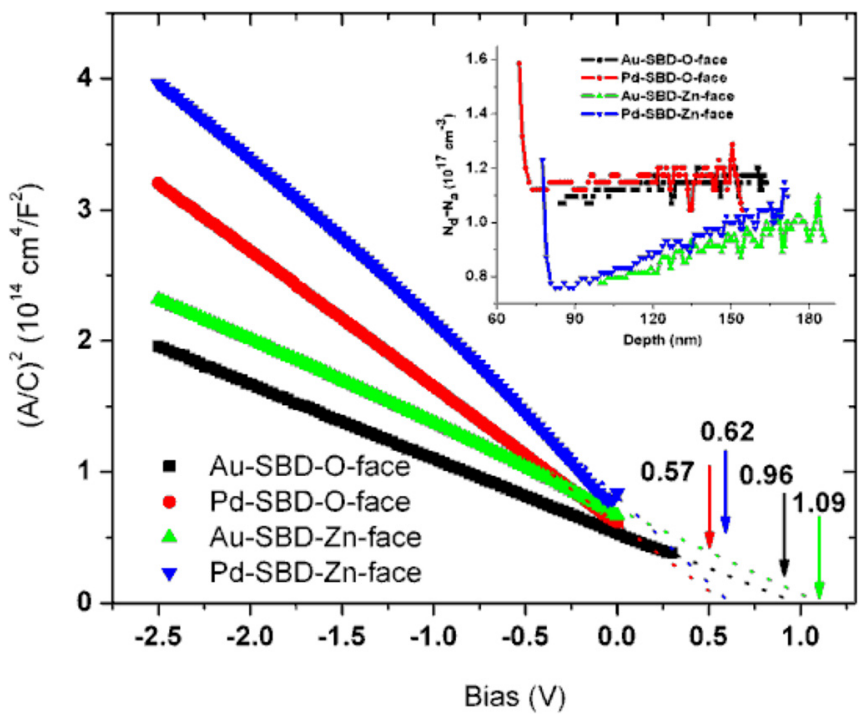

FIg. 7. (Color online) $C^{-2}$ vs $V$ barrier height plots for Au and Pd diodes on $\mathrm{Zn}$ - and O-polar surfaces of ROP-cleaned $\mathrm{ZnO}$. The inset shows corresponding carrier densities vs depth. Higher O-polar diodes exhibit higher subsurface carrier densities and lower $\Phi_{\mathrm{SB}}^{n}$. Reprinted with permission from Y. Dong, Z.-Q. Fang, D. C. Look, G. Cantwell, J. Zhang, J. J. Song, and L. J. Brillson, Appl. Phys. Lett., 93, 072111, 2008. Copyright 2008, American Institute of Physics.

decrease in net carrier density for the Zn-polar surface. The Pd and $\mathrm{Au}$ diodes exhibit similar carrier density profiles, indicating that this contact behavior is due to the different polarity rather than differences in metal. SIMS results showed no differences in any residual impurities between the two polarities. Associated with the increased donor density on the O-polar surface for the $\mathrm{Au}$ diode, DLTS reveals a trap located $0.9 \mathrm{eV}$ below the conduction band $E_{C}$ that increases toward the metal interface. Significantly, the position of this trap corresponds to an energy level $3.36-0.9=2.46 \mathrm{eV}$ above the valence band, nearly identical to the $\sim 2.45 \mathrm{eV}$ defect energy measured by DRCLS. Indeed, SPS features due to filling gap states locate a level at $\sim 2.45 \mathrm{eV}$ above the valence band $E_{V}{ }^{43}$

It is now possible to control the rectifying versus Ohmic nature of $\mathrm{ZnO}$ Schottky barriers by controlling the defect densities with polarity and plasma processing. Figure 8 illustrates schematically a diode of Au deposited on an as-received and chemically cleaned $\mathrm{ZnO}$ surface (Au I) and another Au diode deposited subsequently on the same surface after this surface was exposed to a remote oxygen plasma (ROP) (Au II). The ROP treatment is known to remove surface adsorbates such as $\mathrm{OH}$ and $\mathrm{C}$, remove $\mathrm{H}$ from within the $\mathrm{ZnO}$, and reduce $\sim 2.45 \mathrm{eV}$ emission attributed to $V_{\mathrm{O}} \cdot{ }^{35,49}$ Figure 8(a) shows $1 / C^{2}-V$-derived net electron density and DRCLS spectra obtained from the same depth range on a Zn-polar surface. ${ }^{38}$ For the as-received surface, optical emission from the intimate $\mathrm{Au}-\mathrm{ZnO}$ interface consists of the NBE emission, phonon replicas, and a single gap state feature at $\sim 2.5 \mathrm{eV}$ nearly 3 orders of magnitude lower in intensity. ROP treatment introduces a second gap state at $\sim 2.1 \mathrm{eV}$ attributed to $V_{\mathrm{Zn}}$ according to the results presented in Fig. 6(b). The inset of Fig. 8(a) shows the net electron densities corresponding to these DRCL spectra. For the Au I diode, carrier density remains roughly constant to within $80 \mathrm{~nm}$ of the metal interface. For the Au II diode, carrier density exhibits a pronounced decrease within proximity to the surface. This is clear evidence that the ROP-generated $\sim 2.1 \mathrm{eV}$ emission is due to a compensating acceptor-type defect. Indeed, according to the same analysis used in Fig. 7, the Au II diode exhibits higher rectifying character, as

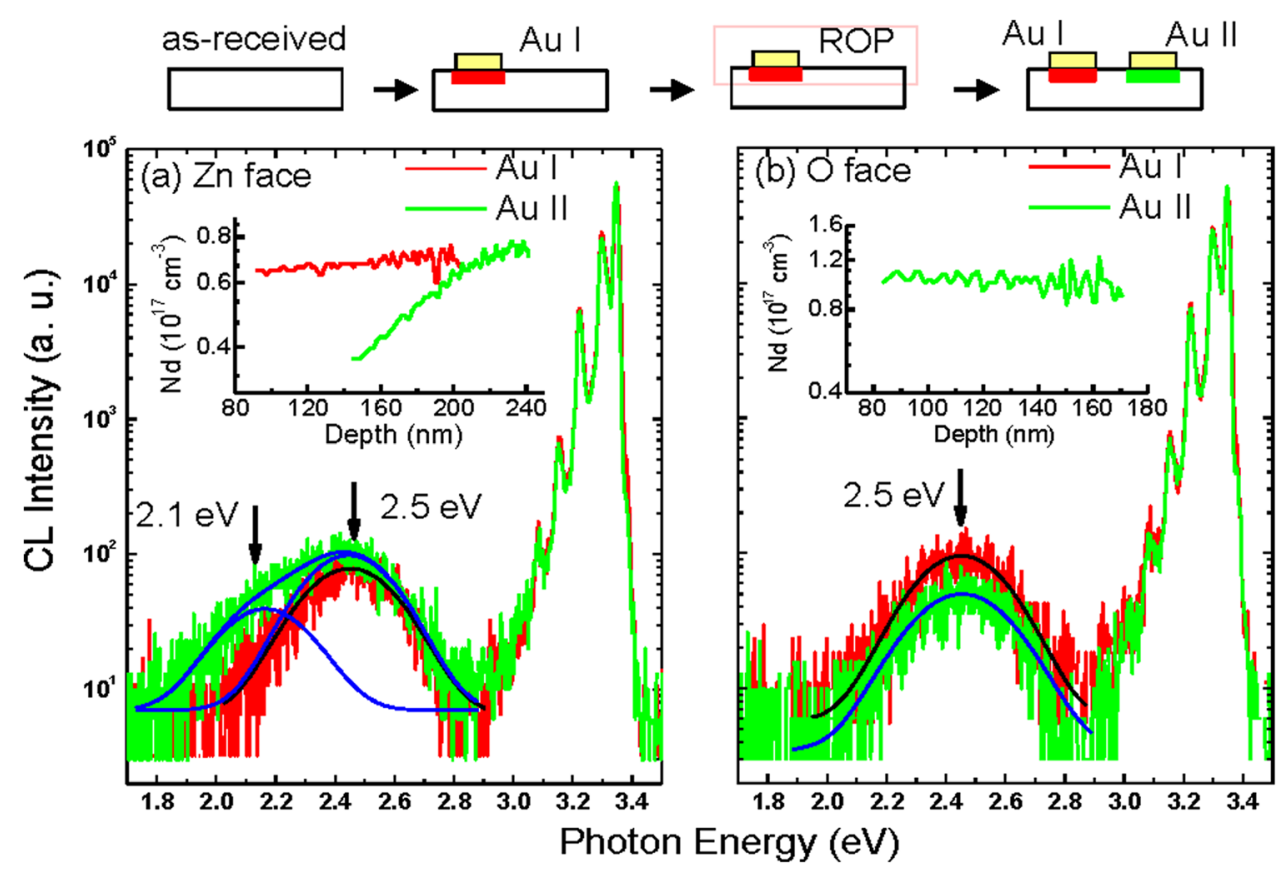

FIG. 8. (Color online) Comparison of micro-CL spectra for Au I and II diodes at their Zn and O-polar interfaces. Without ROP treatment, $\sim 2.5$ eV defect emissions increase at the $\mathrm{Au}-\mathrm{ZnO}(000 \overline{1})$ interface. With ROP treatment, $\sim 2.1 \mathrm{eV}$ defect emission increases at the $\mathrm{Au}-\mathrm{ZnO}(0001)$ interface. The corresponding $C-V$ carrier profiles appear in the inset showing higher electron densities for Au I and O-polar surface diodes. Reprinted with permission from Y. Dong, Z.-Q. Fang, D. C. Look, D. R. Doutt, G. Cantwell, J. Zhang, J. J. Song, and L. J. Brillson., J. Appl. Phys., 108, 103718, 2010. Copyright 2010, American Institute of Physics. 
expected for a lower free carrier density and hence wider barrier width.

As-received and ROP-treated Au diodes formed on the Opolar $\mathrm{ZnO}$ face exhibit significant differences that can account for the lower $\Phi_{\mathrm{SB}}$ shown in Figs. 3 and 7. In Fig. 8(b), Au I diodes exhibit proportionally higher $\sim 2.5 \mathrm{eV}$ emission, which ROP treatment reduces nearly twofold. No $\sim 2.1 \mathrm{eV}$ emission is evident with ROP treatment. The corresponding carrier density for Au II on the O-polar face is higher than on the $\mathrm{Zn}$-polar face. Carrier densities for Au I diodes on the O-polar face were precluded by excessive leakage current, indicating even higher carrier densities than for Au II on the same surface. Thus Fig. 8(b) shows that emissions associated with $V_{\mathrm{O}}$ are higher on the O-polar face and correlate with higher carrier densities below the metal- $\mathrm{ZnO}$ interface.

In general, these interface defect findings show that (1) metal reactions can increase defect densities by orders of magnitude within tens of nanometers of the metal- $\mathrm{ZnO}$ interface; (2) the nature of chemical reaction induces different defects and interfacial layers; (3) surface polarity alters defects and free carrier densities within the surface space charge region; and (4) interface defect densities and Schottky barriers can be controlled by remote plasma techniques.

\section{DEFECT ROLES IN ACHIEVING CONTROLLED DOPING}

There is now great interest in controlled doping of $\mathrm{ZnO}$ to achieve: (1) $p$-type doping for light emitting diodes and lasers and (2) degenerate $n$-type doping for transparent conducting oxides. $p$-type $\mathrm{ZnO}$ is achievable but difficult to control and stabilize over time. Examples include $p-i-n$ homojunctions,${ }^{50} p$-n homojunction light emitting diodes, ${ }^{51}$ and $p-\mathrm{Cu}: \mathrm{ZnO} / n-6 \mathrm{H}: \mathrm{SiC} p-n$ heterojunctions, ${ }^{52}$ each of which emit light with electric current. Very recently, Liu et al. have demonstrated lasing within $\mathrm{ZnO}$ nanorods. ${ }^{53}$ The $p$-type layers in these structures can change with time, suggesting the movement of defects within the semiconductor that change carrier properties. Such electrically active native point defects can act as donors, e.g., $V_{\mathrm{O}}$ complexes or $\mathrm{Zn}$ interstitials $\mathrm{Zn}_{i}$, that can compensate $p$-type dopants, or as acceptors, e.g., $V_{\mathrm{Zn}}$, that can compensate residual donor impurities such as $\mathrm{Al}, \mathrm{In}$, and $\mathrm{Ga}$. Thus native point defects can supply or balance dopant sites. However, the physical nature of defect donors and acceptors that dominate charge densities as well as their behavior under various growth and processing conditions are still unresolved. The ability to correlate optical emissions with the energetics of these defects can help monitor the densities and spatial distributions of electrically active sites in $\mathrm{ZnO}$.

In order to identify specific optical emissions with specific native point defects, we correlated DRCLS measurements with PAS and SIMS of the same crystal films. ${ }^{30}$ DRCLS of hydrothermally grown $\mathrm{ZnO}$, unintentionally doped with $5 \times 10^{17} \mathrm{Li} / \mathrm{cm}^{3}, n$-type and highly resistive, were implanted with ${ }^{7} \mathrm{Li}^{+}$and annealed under controlled conditions. ${ }^{54,55}$ The preannealed $\mathrm{ZnO}$ exhibited midgap defect and NBE emissions that were relatively uniform with depth. With a $20 \mathrm{~ms} 1200^{\circ} \mathrm{C}$ flash anneal, DRCLS indicates orders-of-magnitude increases in deep level emissions at $\sim 2$ and $\sim 2.45 \mathrm{eV}$ with the former dominating at all depths. In contrast, a $1 \mathrm{~h} 800^{\circ} \mathrm{C}$ furnace anneal reverses this behavior, with the $\sim 2.4 \mathrm{eV}$ emission larger at all depths. Both emissions vary with depth for both processes, and the large differences in their magnitude and variation with depth for the same starting material demonstrate the strong effect of different annealing conditions.

Since both DRCLS and PAS provide defect information as a function of depth, we compared the results of both for the same crystal films. Figure 9 illustrates schematically the comparison of the two techniques and the data obtained. For DRCLS, an incident electron beam generates secondary electrons and ultimately electron-hole pairs that can recombine and emit light at depths calculated from Monte Carlo simulations. For PAS, an incident positron beam emitted with a $1.27 \mathrm{MeV} \gamma$ ray penetrates the solid and thermalizes until it recombines with an electron and emits two $0.51 \mathrm{eV} \gamma$ rays. As with electrons, the depth of excitation can be controlled with the kinetic energy of the incident positron. The time elapsed between the initial and final $\gamma$ ray emissions determines the lifetime of the recombination, increasing for regions with low densities of electrons such as $V_{\mathrm{Zn}}$ sites and thus providing a measure of vacancy density. The $0.51 \mathrm{MeV}$ line shape or $S$ parameter reflects the annihilating electron's Doppler shift and provides a measure of its momentum, which is useful for distinguishing between different open volume defects. For the crystal flash annealed at $1200^{\circ} \mathrm{C}$,

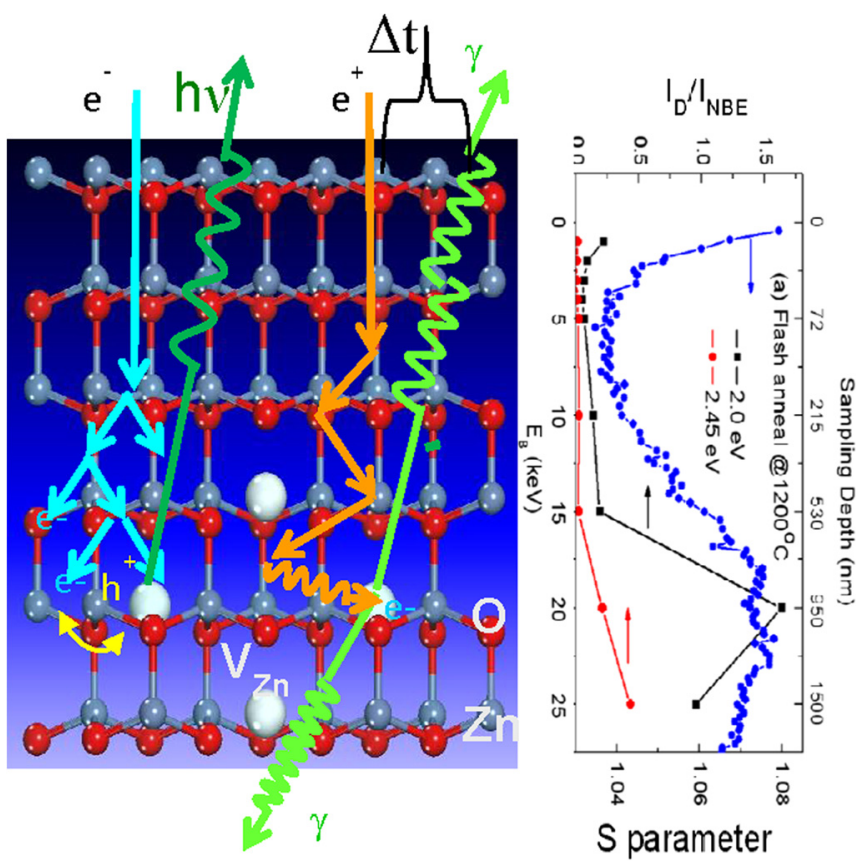

FIG. 9. (Color online) (a) Schematic illustration comparing DRCLS and PAS excitation mechanisms vs depth from the free surface. (b) DRCLS defect emission intensities and PAS $V_{\mathrm{Zn}}$ densities vs depth for $1200^{\circ} \mathrm{C}$ flash annealed $I(2.0 \mathrm{eV}) / I(3.4 \mathrm{eV})$ (black square) and $I(2.4 \mathrm{eV}) / I(3.4 \mathrm{eV})$ (red hexagons) vs $V_{\mathrm{Zn}}$ (blue dots), showing the $2.0 \mathrm{eV}$ emissions correlate with $V_{\mathrm{Zn}}$. Reprinted with permission from Y. Dong, F. Tuomisto, B. G. Svensson, A. Yu. Kuznetsov, and L. J. Brillson, Phys. Rev. B, 81, 081201, 2010. Copyright 2010, American Institute of Physics. 
the $S$ parameter versus sample depth shows a $V_{\mathrm{Zn}}$ concentration peaking at $\sim 1 \mu \mathrm{m}$. This feature is not due to implanted Li density, which peaks considerably deeper, i.e., $\sim 1.6 \mu \mathrm{m} .{ }^{55}$ The graph in Fig. 9 comparing PAS $S$ parameter with $\sim 2.0$ and $\sim 2.45 \mathrm{eV}$ DRCLS emissions shows a clear correspondence between the $V_{\mathrm{Zn}}$ density and the $\sim 2.0 \mathrm{eV}$ emission intensity. Conversely, the $\sim 2.45 \mathrm{eV}$ peak intensity does not. Similar PAS-DRCLS comparison for the $800^{\circ} \mathrm{C}$ furnace annealed sample yields the same results-good correlation between $V_{\mathrm{Zn}}$ and $\sim 2.0 \mathrm{eV}$ emission intensities and strikingly different behavior for the $\sim 2.45 \mathrm{eV}$ intensities. ${ }^{30}$ Similar correlations with other $\mathrm{ZnO}$ films also show a variation of the $\sim 2 \mathrm{eV}$ peak energy with $V_{\mathrm{Zn}}$ cluster size, ranging from $1.6 \mathrm{eV}$ for isolated $V_{\mathrm{Zn}}$ to $\sim 2 \mathrm{eV}$ for $V_{\mathrm{Zn}}$ clusters. ${ }^{30}$ The different $\sim 2.45 \mathrm{eV}$ behavior suggests that this feature is related to the other dominant defect in $\mathrm{ZnO}, V_{\mathrm{O}}$ or a $V_{\mathrm{O}}$ complex. Considerable previous work supports this assignment. ${ }^{36,56}$

In order to determine the energy levels within the $\mathrm{ZnO}$ bandgap that correspond to the $\sim 2$ and $\sim 2.45 \mathrm{eV}$ emissions, we employed SPS to identify energies corresponding to optical transitions between gap states and $E_{C}$ versus gap states and $E_{V}$. These measurements revealed that $\sim 2 \mathrm{eV}$ optical excitation depopulates electrons from states located $2 \mathrm{eV}$ below $E_{C}$, while $\sim 2.45 \mathrm{eV}$ excitation populates states located $\sim 2.45 \mathrm{eV}$ above $E_{V}$ with electrons. These processes result in opposite changes in work function as the surface band bending and Fermi level $E_{F}$ vary with changing concentration of electrons at the surface. The resultant energy level assignments can be compared with theory. In particular, the 1.6-2 eV level for $V_{\mathrm{Zn}}$ and $V_{\mathrm{Zn}}$ clusters below the conduction band can be compared with calculations of the $V_{\mathrm{Zn}} 0 /-$ transition obtained from plane wave pseudopotential total-energy and force methods plus local density approximation, ${ }^{57}$ firstprinciples, hybrid functional with finite size corrections, ${ }^{45}$ and density functional theory within a local density approximation, ${ }^{58}$ which yield a wide range of values, i.e., $\sim 3.8, \sim 2.7$, and $\sim 3.2 \mathrm{eV}$ below $E_{C}$, respectively. Hence our energy level assignments can provide a guide for assessing different calculational approaches.

The depth dependence of optical emissions attributed to $V_{\mathrm{Zn}^{-}}$and $V_{\mathrm{O}^{-}}$-related defects provides a useful tool to understand surface spreading resistance measurements (SSRM) for the $\mathrm{ZnO}$ films with DRCLS-PAS correlations. With the expectation that $V_{\mathrm{Zn}}$ act as acceptors to increase $\rho$, that $V_{\mathrm{Zn}}$ clusters deactivate $\mathrm{Li}$ acceptors to decrease $\rho$, and that $V_{\mathrm{O}}$-related complexes act as donors to decrease $\rho,{ }^{30}$ one can account for the SSRM variations of $\rho$ with depth for dramatically different $\rho$ variations on a nanometer scale. ${ }^{55}$ The success of these DRCLS-SSRM correlations requires that a combination of defects be used to account for nanoscale resistivity variations.

In general then, DRCLS-PAS correlations provide an identification of the commonly observed $\sim 2 \mathrm{eV}$ as $V_{\mathrm{Zn}}$ clusters and the $\sim 1.6-1.7 \mathrm{eV}$ emissions as isolated $V_{\mathrm{Zn}}$. SPS provides a determination of the energy levels corresponding to the DRCLS emissions that can be used for comparison with theory. Different annealing methods alter $V_{\mathrm{Zn}}$ and $V_{\mathrm{Zn}}$ clus- ter distributions spatially in ion-implanted $\mathrm{ZnO}$, and a combination of $V_{\mathrm{Zn}}, V_{\mathrm{Zn}}$ clusters, and $V_{\mathrm{O}}$-related defects are required to account for $\rho$ versus depth variations on a nanometer scale.

With these defect assignments, the role of vacancies in $\mathrm{ZnO}$ doping can be further understood. Figure 10 illustrates the interplay between $V_{\mathrm{Zn}}$-related emissions measured by DRCLS and Hall-measured carrier density for $\mathrm{ZnO}$ degenerately doped with Ga, termed "GZO." ${ }^{59}$ This material exhibits carrier densities and mobilities that rival the leading transparent conducting oxide, indium tin oxide. ${ }^{34,60,61}$ Previously we showed from SIMS and Hall measurements that donors in GZO can only be due to $\mathrm{Ga}$ on $\mathrm{Zn}$ sites, $\mathrm{Ga}_{\mathrm{Zn}}$, since residual donor impurity densities are orders of magnitude lower. ${ }^{33}$ Similarly, SIMS measurements and the application of density functional theory show that acceptors in GZO can be explained only by $V_{\mathrm{Zn}}$ and not by any other impurity. The inset of Fig. 10 contains DRCLS spectra for a GZO sample with an electron density of $4.92 \times 10^{20} \mathrm{~cm}^{-3}$ grown at $400^{\circ} \mathrm{C}$ by PLD in a forming gas (FG) atmosphere. The degenerate $n$-type $\mathrm{ZnO}$ spectra show both $V_{\mathrm{Zn}}$-related features at $1.84-2.05 \mathrm{eV}$ and emission at energies above the conduction band minimum due to transitions involving filled conduction band states. Figure 10 includes data from GZO samples grown under both $\mathrm{Ar}$ and FG atmosphere at various temperatures ranging from 100 to $600^{\circ} \mathrm{C}$. $V_{\mathrm{Zn}}$ intensities normalized to intensity at $3 \mathrm{eV}$ (shown) or integrated conduction band intensity ${ }^{59}$. both show a monotonic decrease with increasing Hall carrier density $n_{\text {Hall }}$ over a range $1-10 \times 10^{20} \mathrm{~cm}^{-3}$. The $3 \mathrm{eV}$ intensity reflects conduction band intensity near the renormalized band edge and appears in the inset as a shoulder on the leading edge of conduction band emission. Integrated area $1.84-2.05 \mathrm{eV}$ versus full conduction band emissions yield almost exactly the same ratios. ${ }^{59}$. This decreasing intensity of $V_{\mathrm{Zn}}$ and $V_{\mathrm{Zn}}$ clusters with increasing $n_{\text {Hall }}$ thus demonstrates

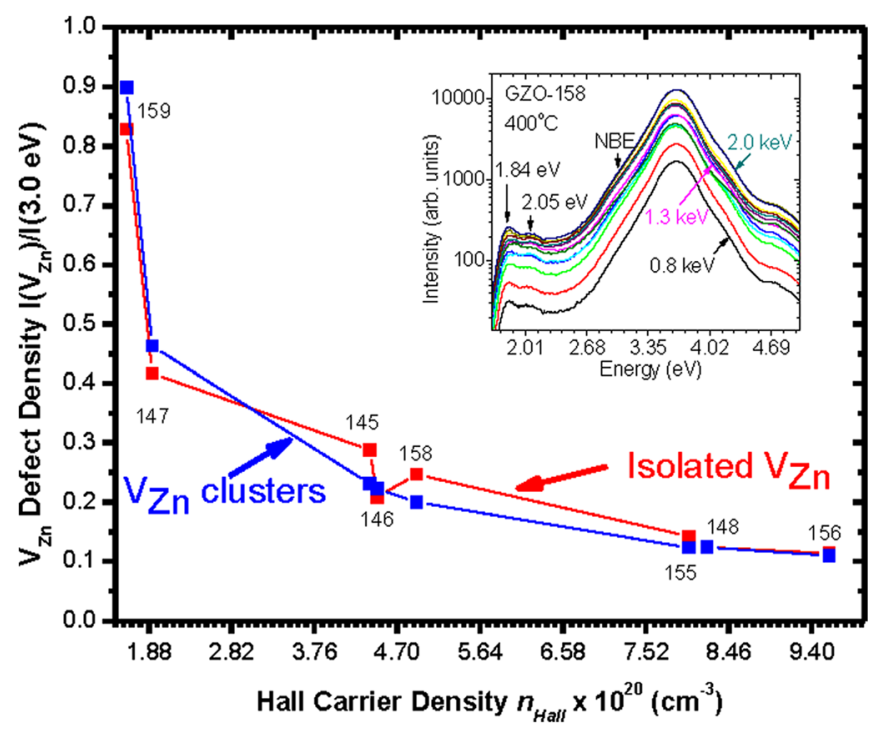

FIG. 10. (Color online) $V_{\mathrm{Zn}}$-related defect intensity $I\left(V_{\mathrm{Zn}}\right) / I(3.0 \mathrm{eV})$ vs Hall carrier density $n_{\text {Hall }}$ for degenerately doped GZO crystals showing decreasing $V_{\mathrm{Zn}}$ with increasing $n_{\mathrm{Hall}}$ indicating $\mathrm{Ga}$ filling $\mathrm{Zn}$ vacancies. The inset contains DRCLS spectra showing both $V_{\mathrm{Zn}}$-related and filled conduction band states. High energy emission cutoff provides $E_{F}$ vs depth. 
the filling of $\mathrm{Zn}$ vacancies by $\mathrm{Ga}$ that increase $\mathrm{Ga}_{\mathrm{Zn}}$ donors and decrease $V_{\mathrm{Zn}}$ acceptors. This relation holds for both $\mathrm{Ar}$ and FG growth ambients. The highest electron density occurs for GZO grown at $200^{\circ} \mathrm{C}$ for both ambients and decreases with increasing growth temperature. The temperature dependence of dopant incorporation depends on the dynamics of the growth process ${ }^{60}$ and the availability of $V_{\mathrm{Zn}}$ sites. Hence this interplay suggests growth strategies for maximizing donor dopant incorporation.

The DRCL spectra shown in the inset of Fig. 10 provide a measure of $E_{F}$ from the high energy cutoff of emission intensity. The energy at which conduction band emission decreases to $50 \%$ of its maximum provides a Fermi level position $E_{F \max }$ from which filled conduction band state densities can be calculated, depending on the electron effective mass $m^{*}$ and the shape of the renormalized conduction band. ${ }^{62}$ Comparison of $E_{F \max }$ with absorption threshold measurements of $E_{F}-E_{V}$ on the same samples shows consistently higher $E_{F \max }$ energies that vary with probe depth. The difference between absorption threshold and $E_{F \max }$ can be understood if carrier density varies within the absorption depth since the onset of absorption occurs at $E_{F}-E_{V}$ minima while conduction-to-valence band free carrier recombination can extend to energies where doping and hence $E_{F \max }-E_{V}$ is higher. DRCLS measurements of $E_{F \max }$ versus depth indeed reveal variations in free carrier density. ${ }^{60}$ Furthermore, the $V_{\mathrm{Zn}}$-related intensities exhibit an anticorrelation with $E_{F \max }$, decreasing for depths at which $E_{F \max }$ is high and vice versa. ${ }^{60}$ These $V_{\mathrm{Zn}}$-related intensities vary by nearly a factor of 2 with depth on a scale of tens of nanometers versus $E_{F \max }$ variations that correspond to $\leq 10 \%$ variations in carrier density, precise values depending on the renormalized conduction band shape

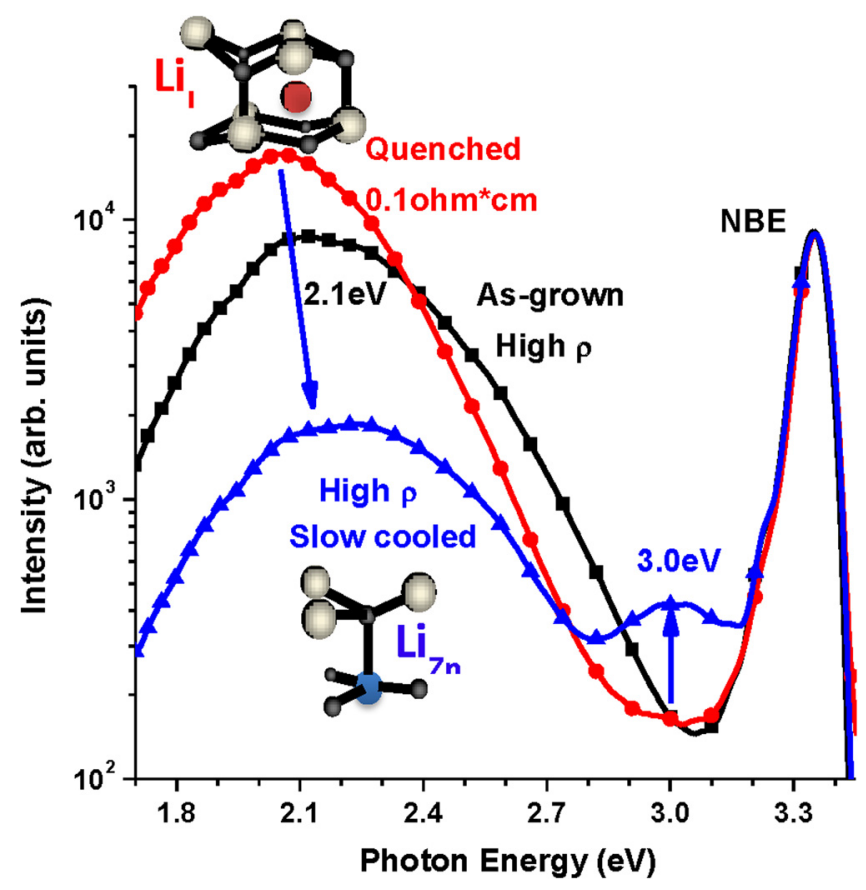

FIG. 11. (Color online) $5 \mathrm{keV} \mathrm{CL}$ spectra comparison of $V_{\mathrm{Zn}^{-}}$and $\mathrm{Li}_{\mathrm{Zn}^{-}}$ related defects in Li-doped MG-ZnO after quenching and slow cooling process. The slow-cooled MG-ZnO exhibits an additional $3.0 \mathrm{eV}$ peak and a decrease of $V_{\mathrm{Zn}}$-related defect intensity.
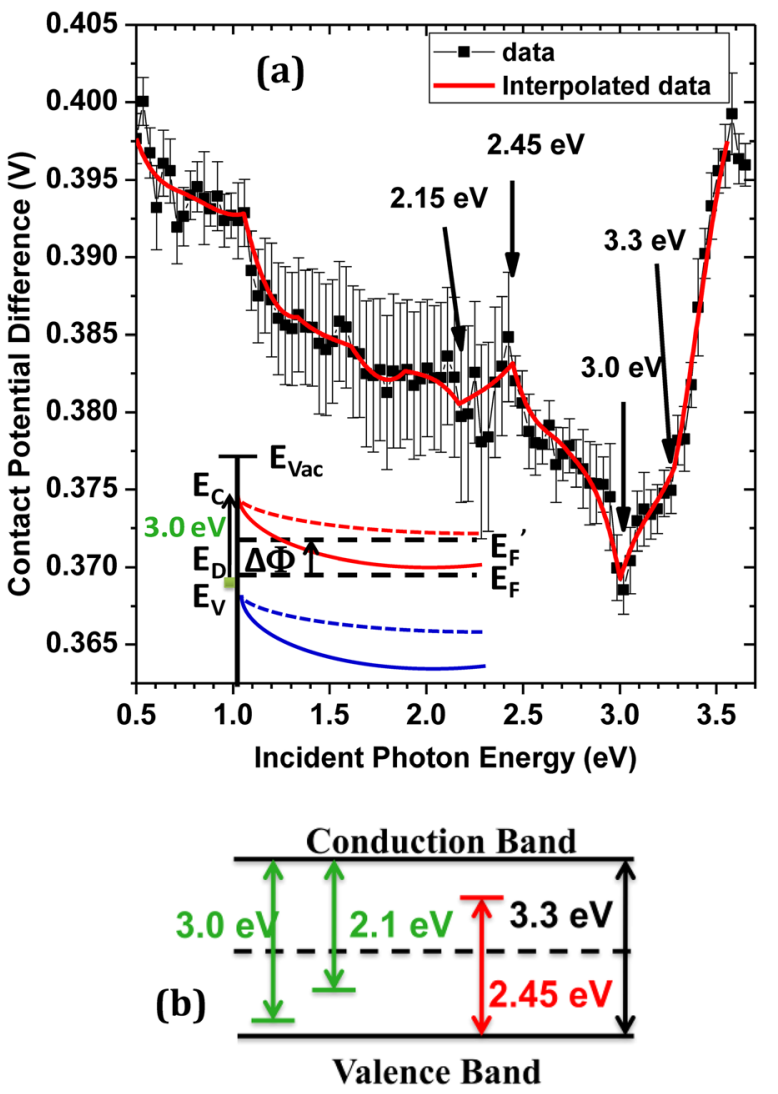

FIG. 12. (Color online) (a) SPS spectra showing pronounced cpd increase at $3.0 \mathrm{eV}$ corresponding to surface gap state emptying and (inset) lower band bending, raising $E_{F}$ in the gap.(b) Schematic optical transitions for $V_{\mathrm{Zn}}$ $(2.1 \mathrm{eV}), V_{\mathrm{O}}$-related $(2.45 \mathrm{eV})$, and $\mathrm{Li}_{\mathrm{Zn}}(3.0 \mathrm{eV})$ defects in a $\sim 3.3 \mathrm{eV} \mathrm{ZnO}$ bandgap, showing energy level positions for the corresponding defects.

but consistent with the magnitude of Hall-measured acceptor densities. ${ }^{60}$ This anticorrelation further confirms the acceptor nature of the $V_{\mathrm{Zn}}$-related emissions, and the $E_{F \max }$ profile identifies primary Hall conduction channels for modeling donor and acceptor densities.

Another example of interplay between dopants and defects is $\mathrm{Li}$-doped $\mathrm{ZnO}$, where $\mathrm{Li}$ on a $\mathrm{Zn}$ site $\mathrm{Li}_{\mathrm{Zn}}$ acts as an acceptor. Figure 11 illustrates DRCL spectra for Li-doped $\mathrm{ZnO}$ normalized to constant NBE intensity. ${ }^{63}$ This hydrothermally (HT) grown HT-ZnO was unintentionally doped with $1 \sim 5 \times 10^{17} \mathrm{Li} / \mathrm{cm}^{3}$ and annealed in $10 \% \mathrm{Li}_{2} \mathrm{O}$ and $\mathrm{ZnO}$ powder for $1 \mathrm{~h}$ then either (1) quenched in de-ionized $\mathrm{H}_{2} \mathrm{O}$ or (2) annealed in air at $600{ }^{\circ} \mathrm{C}$ for an additional $10 \mathrm{~min}$ with slow cooling in air. The as-grown crystals exhibit high resistivity $\rho$ and high $V_{\mathrm{Zn}}$-related emission at $\sim 2.1 \mathrm{eV}$. Rapid quenching decreased $\rho$ to $0.1 \Omega \mathrm{cm}$ and increased $V_{\mathrm{Zn}^{-}}$ related emission. On the other hand, additional $10 \mathrm{~min}$ annealing and slow cooling in air produces high $\rho$, decreased $V_{\mathrm{Zn}}$-related emission, and the appearance of a new peak at $3.0 \mathrm{eV}$. The intensity of this $3.0 \mathrm{eV}$ peak varies with depth with a profile that mirrors the $\mathrm{Li}$ density [Li] measured by SIMS. Furthermore, the [Li] profile follows the SSRM depth profile of $\rho$, indicating that the $3.0 \mathrm{eV}$ DRCLS peak intensity follows the $\mathrm{Li}_{\mathrm{Zn}}$ acceptor density.

The energy level position of this $3.0 \mathrm{eV}$ emission follows from SPS spectra of the same Li-doped ZnO. Figure 12(a) 
illustrates a strong onset of contact potential difference (cpd) at $3.0 \mathrm{eV}$ that corresponds to optical transitions that empty traps located $3.0 \mathrm{eV}$ below $E_{C}$. The inset of Fig. 12 illustrates how emptying negative charge from this state reduces $n$-type band bending and raises $E_{F}$ toward the vacuum level $E_{\mathrm{VAC}}$. Slope changes are also apparent at 2.15 and $2.45 \mathrm{eV}$ corresponding to emptying and filling transitions involving $V_{\mathrm{Zn}^{-}}$ and $V_{\mathrm{O}}$-related defects, respectively. The position of the $\mathrm{Li}_{\mathrm{Zn}}$ acceptor level agrees with theoretical predictions ${ }^{64}$ and with photoluminescence spectroscopy features of Li diffused into ZnO. ${ }^{65}$ Figure 12(b) illustrates all three transitions within the $\mathrm{ZnO}$ bandgap. As with Ga-doped $\mathrm{ZnO}$, these results for Li-doped $\mathrm{ZnO}$ illustrate how $V_{\mathrm{Zn}}$-related defect densities decrease as zinc vacancy sites are filled with Li. The major difference in $\mathrm{Li}$ incorporation between quenched and slowcooled samples can be viewed in terms of the time required for Li to diffuse to $V_{\mathrm{Zn}}$ sites. Without sufficient time to diffuse, $\mathrm{Zn}$ atoms remain as interstitials that act as donors, reducing $\rho$ as observed experimentally.

\section{CONCLUSIONS}

The results presented here serve to illustrate numerous ways in which native point defects play a major role in $\mathrm{ZnO}$ Schottky barrier formation and doping. Native point defect densities near $\mathrm{ZnO}$ and other semiconductor interfaces are much higher than previously believed. Their electrical activity introduces additional free carriers that reduce depletion widths and increase tunneling, while the defect gap states themselves provide sites for hopping conduction through barriers. The densities of these native defects and free carriers are sufficient to dominate charge transport across metal-semiconductor interfaces. Chemical interactions between metals and $\mathrm{ZnO}$ produce new defects at their intimate junction whose physical nature depends on the metal interaction with $\mathrm{Zn}$ or $\mathrm{O}$ in the adjacent lattice. DRCLS studies identify optical signatures of $V_{\mathrm{Zn}}, V_{\mathrm{Zn}}$ clusters, $V_{\mathrm{O}}$-complexes, $\mathrm{Ga}_{\mathrm{Zn}}$, and $\mathrm{Li}_{\mathrm{Zn}}$ defects whose distributions depend sensitively on annealing. Therefore DRCLS serves as a tool for monitoring these defects to optimize Schottky barriers and to enable $n$ - or $p$-type doping. New avenues to control densities and spatial distributions of native point defects are now available using the plasma, annealing, and metal bonding techniques illustrated here.

\section{ACKNOWLEDGMENTS}

The authors gratefully acknowledge support of the National Science Foundation, Grant No. DMR-0803276 (Charles Ying and Verne Hess), the Research Council of Norway, and the Academy of Finland. DCL also acknowledges support from AFOSR (James Hwang) and DOE (Refik Kortan).

${ }^{1}$ S. J. Pearton, D. P. Norton, K. Ip, Y. W. Heo, and T. Steiner, Prog. Mater. Sci. 50, 293 (2005).

${ }^{2}$ D. C. Look, Mater. Sci. Eng., B 80, 383 (2001).

${ }^{3}$ M. Grundmann, H. Frenzel, A. Lajn, M. Lorenz, F. Schein, and H. von Wenckstern, Phys. Status Solidi A 207, 1437 (2010).
${ }^{4}$ Ü. Özgür, Ya. I. Alivov, C. Liu, A. Teke, M. A. Reshchikov, S. Doðan, V. Avrutin, S.-J. Cho, and H. Morkoç, J. Appl. Phys. 98, 041301 (2005).

${ }^{5}$ M. D. McCluskey and S. J. Jokela, J. Appl. Phys. 106, 071101 (2009).

${ }^{6}$ B. K. Meyer et al., Phys. Status Solidi B 241, 231-170 (2004); B. K. Meyer, D. M. Hofmann, J. Stehr, and A. Hoffmann, in Zinc Oxide Materials for Electronic and Optoelectronic Device Applications, edited by C. W. Litton, D. C. Reynolds, and T. C. Collin (Wiley, Chichester, UK., 2011), Chap. 6, pp. 135-170.

${ }^{7}$ L. J. Brillson and Y. Lu, J. Appl. Phys. 109, 121301 (2011).

${ }^{8}$ L. J. Brillson, in Zinc Oxide Materials for Electronic and Optoelectronic Device Applications, edited by C. W. Litton, D. C. Reynolds, and T. C. Collin (Wiley, Chichester, UK., 2011), Chap. 4, pp. 87-112.

${ }^{9}$ L. J. Brillson, in Surfaces and Interfaces of Electronic Materials (WileyVCH, Weinheim, 2010), Chap. 21, pp. 447-522.

${ }^{10}$ G. Heiland, Surf. Sci. 13, 72 (1969).

${ }^{11}$ M. W. Allen, S. M. Durbin, and J. B. Metson, Appl. Phys. Lett. 91, 053512 (2007).

${ }^{12}$ B. G. Streetman and S. K. Banerjee, Solid State Electronic Devices, 6th ed. (Pearson Prentice-Hall, Upper Saddle River, NJ, 2006), pp. 221-223.

${ }^{13}$ A. Schenk and U. Krumbein, J. Appl. Phys. 78, 3185 (1995).

${ }^{14}$ A. G. Chynoweth, W. L. Feldmann, and R. A. Logan, Phys. Rev. 121, 684 (1961).

${ }^{15}$ T. Yajima and L. Esaki, J. Phys. Soc. Jpn. 13, 1281 (1958).

${ }^{16}$ O. Breitenstein, P. Altermatt, K. Ramspeck, and A. Schenk, Proceedings of the 21 st European Photovoltaic Solar Energy Conference, 4-8 September 2006, Dresden, Germany (WIP, Munich, 2006), pp. 625-628.

${ }^{17}$ M. W. Allen, M. M. Alkaisi, and S. M. Durbin, Appl. Phys. Lett. 89, 103520 (2006).

${ }^{18}$ K. Hong and J.-L. Lee, Electrochem. Solid-State Lett. 11, H29 (2007).

${ }^{19}$ H. Von Wenckstern, G. Biehne, R. A. Rahman, H. Hochmuth, M. Lorenz, and M. Grundmann, Appl. Phys. Lett. 88, 092102 (2006).

${ }^{20}$ C. A. Mead, Solid-State Electron. 9, 1023 (1966).

${ }^{21}$ L. J. Brillson, Phys. Rev. B 18, 2431 (1978).

${ }^{22}$ L. J. Brillson, Phys. Rev. Lett. 40, 260 (1978).

${ }^{23}$ S. J. Pearton, D. P. Norton, K. Ip, Y. W. Heo, and T. Steiner, Superlattices Microstruct. 34, 3 (2003).

${ }^{24}$ S. M. Sze, Physics of Semiconductor Devices, 3rd ed. (Wiley-Interscience, New York, 2007), Chap. 5.

${ }^{25}$ F. A. Padovani and R. Stratton, Solid-State Electron. 9, 695 (1966).

${ }^{26}$ L. J. Brillson, J. Vac. Sci. Technol. B 19, 1762 (2001).

${ }^{27}$ L. J. Brillson, H. L. Mosbacker, D. Doutt, M. Kramer, Z. L. Fang, D. C. Look, G. Cantwell, J. Zhang, and J. J. Song, Superlattices Microstruct. 45, 206 (2009); L. J. Brillson, Y. Dong, D. Doutt, D. C. Look, and Z.-Q. Fang, Physica B 404, 4768 (2009); D. Doutt, H. L. Mosbacker, G. Cantwell, J. Zhang, J. J. Song, and L. J. Brillson, Appl. Phys. Lett. 94, 042111 (2009).

${ }^{28}$ L. J. Brillson, in Surfaces and Interfaces of Electronic Materials (WileyVCH, Weinheim, 2010), Chap. 16, pp. 279-304.

${ }^{29}$ P. Hovington, D. Drouin, and R. Gauvin, Scanning 19, 1 (1997).

${ }^{30}$ Y. Dong, F. Tuomisto, B. G. Svensson, A. Yu. Kuznetsov, and L. J. Brillson, Phys. Rev. B 81, 081201 (2010).

${ }^{31}$ F. Tuomisto, in Springer Handbook of Crystal Growth, Defects and Characterization, edited by G. Dhanaraj, K. Byrappa, V. Prasad, and M. Dudley (Springer, New York, 2010).

${ }^{32}$ R. Krause-Rehberg and H. S. Leipner, Positron Annihilation in Semiconductors (Springer, New York, 1999).

${ }^{33}$ D. C. Look, K. D. Leedy, L. Vines, B. G. Svensson, A. Zubiaga, F. Tuomisto, D. R. Doutt, and L. J. Brillson, Phys. Rev. B 84, 115202 (2011).

${ }^{34}$ D. C. Look, K. D. Leedy, D. H. Tomich, and B. Bayraktaroglu, Appl. Phys. Lett. 96, 062102 (2010).

${ }^{35}$ H. L. Mosbacker, Y. M. Strzhemechny, B. D. White, P. E. Smith, D. C. Look, D. C. Reynolds, C. W. Litton, and L. J. Brillson, Appl. Phys. Lett. 87, 012102 (2005).

${ }^{36}$ L. J. Brillson, H. L. Mosbacker, M. J. Hetzer, Y. Strzhemechny, G. H. Jessen, D. C. Look, G. Cantwell, J. Zhang, and J. J. Song, Appl. Phys. Lett. 90, 102116 (2007).

${ }^{37}$ Y. Dong, Z.-Q. Fang, D. C. Look, G. Cantwell, J. Zhang, J. J. Song, and L. J. Brillson, Appl. Phys. Lett. 93, 072111 (2008).

${ }^{38}$ Y. Dong, Z.-Q. Fang, D. C. Look, D. R. Doutt, G. Cantwell, J. Zhang, J. J. Song, and L. J. Brillson, J. Appl. Phys. 108, 103718 (2010).

${ }^{39}$ Y. Dong, Z.-Q. Fang, D. C. Look, D. R. Doutt, M. J. Hetzer, and L. J. Bril1son, J. Vac. Sci. Technol. B 27, 1710 (2009).

${ }^{40}$ Z.-Q. Fang, B. Claflin, D. C. Look, Y.-F. Dong, and L. J. Brillson, J. Vac. Sci. Technol. B 27, 1774 (2009); Z.-Q. Fang, B. Claflin, D. C. Look, Y.-F. 
Dong, H. L. Mosbacker and L. J. Brillson, J. Appl. Phys. 104, 063707 (2008).

${ }^{41}$ A. Hierro, S. A. Ringel, M. A. Hansen, U. Mishra, S. Denbaars, and J. Speck, Appl. Phys. Lett. 76, 3064 (2000).

${ }^{42}$ L. J. Brillson, Surf. Sci. 51, 45 (1975).

${ }^{43}$ T. A. Merz, D. R. Doutt, T. Bolton, Y. Dong, and L. J. Brillson, Surf. Sci. Lett. 605, L20 (2011)

${ }^{44}$ A. F. Kohan, G. Ceder, D. Morgan, and C. Van de Walle, Phys. Rev. B 61, 15019 (2000).

${ }^{45}$ F. Oba, A. Togo, Isao Tanaka, Joachim Paier, and Georg Kresse, Phys. Rev. B 77, 245202 (2008).

${ }^{46}$ H. L. Mosbacker et al., J. Vac. Sci. Technol. B 24, 1405 (2007).

${ }^{47}$ U. Grossner, S. Gabrielsen, T. M. Børseth, J. Grillenberger, A. Yu. Kuznetsov, and B. G. Svensson, Appl. Phys. Lett. 85, 2259 (2004).

${ }^{48}$ M. Hansen, Constitution of Binary Alloys (McGraw-Hill, New York, 1958), p. 642.

${ }^{49}$ Y. M. Strzhemechny et al., Appl. Phys. Lett. 84, 2545 (2004).

${ }^{50}$ A. Tsukazaki, M. Kubota, A. Ohtomo, T. Onuma, K. Ohtani, H. Ohno, S. F. Chichibu, and M. Kawasaki, Jpn. J. Appl. Phys., Part 2 44, L643 (2005).

${ }^{51}$ S. J. Jiao et al., Appl. Phys. Lett. 88, 031911 (2006).

${ }^{52}$ J. B. Kim, D. Byun, S. Y. Ie, D. H. Park, W. K. Choi, Ji.-W. Choi, and B. Angadi, Semicond. Sci. Technol. 23, 095004 (2008).

${ }^{53}$ S. Chu et al., Nat. Nanotechnol. 6, 506 (2011).
${ }^{54}$ T. Moe Børseth, F. Tuomisto, J. S. Christensen, W. Skorupa, E. V. Monakhov, B. G. Svensson, and A. Yu. Kuznetsov, Phys. Rev. B 74, 161202 (2006).

${ }^{55}$ T. Moe Børseth, F. Tuomisto, J. S. Christensen, W. Skorupa, E. V. Monakhov, B. G. Svensson, and A. Yu. Kuznetsov, Phys. Rev. B 77, 045204 (2008).

${ }^{56}$ K. Vanheusden, C. H. Seager, W. L. Warren, D. R. Tallant, and J. A. Voigt, Appl. Phys. Lett. 68, 403 (1996).

${ }^{57}$ S. B. Zhang, S.-H. Wei, and Alex Zunger, Phys. Rev. B 63, 075205 (2001).

${ }^{58}$ A. Janotti and C. G. Van de Walle, Phys. Rev. B 76, 165202 (2007).

${ }^{59}$ D. R. Doutt, L. Isabella, K. D. Leedy, and D.C. Look, "Impact of native point defects and Ga diffusion on electronic droperties of degenerate Gadoped ZnO," Appl. Phys. Lett. (submitted).

${ }^{60}$ D. C. Look, T. C. Droubay, J. S. McCloy, Z. Zhu, and S. A. Chambers, J. Vac. Sci. Technol. A 29, 03A102 (2011).

${ }^{61}$ R. C. Scott, K. D. Leedy, B. Bayraktaroglu, D. C. Look, and Y.-H. Zhang, Appl. Phys. Lett. 97, 072113 (2010).

${ }^{62}$ A. Walsh, J. L. F. Da Silva, and S.-H. Wei, Phys. Rev. B 78, 075211 (2008).

${ }^{63}$ Z. Zhang, T. Merz, K.-E. Knutsen, A. Yu. Kuznetsov, B. G. Svensson, and L. J. Brillson, Appl. Phys. Lett. 100, 042107 (2012).

${ }^{64}$ S. Lany and A. Zunger, Appl. Phys. Lett. 96, 142114 (2010).

${ }^{65}$ B. K. Meyer, J. Stehr, A. Hofstaetter, N. Volbers, A. Zeuner, and J. Sann, Appl. Phys. A: Mater. Sci. Process. 88, 119 (2007). 